\title{
CDISC SDTM Nutrition Findings About Test Name Terminology
}

National Cancer Institute

\section{Source}

National Cancer Institute. CDISC SDTM Nutrition Findings About Test Name

Terminology. NCl Thesaurus. Code C154686.

Terminology associated with the nutrition findings about test name codelist of the Clinical Data Interchange Standards Consortium (CDISC) Study Data Tabulation Model (SDTM). 